DOI: $10.17805 /$ trudy.2020.2.7

\title{
АНАЛИЗ ЭФФЕКТИВНОСТИ ИСПОЛЬЗОВАНИЯ ОСНОВНЫХ ПРОИЗВОДСТВЕННЫХ ФОНДОВ (НА ПРИМЕРЕ 000 «УК ПРОДИМЕКС - САХАР»)
}

\author{
Е. Г. Петрова \\ Московский гуманитарный университет \\ Аннотация: В статье рассмотрены показатели деятельности $О О О$ «УК ПРОДИМЕКС - Сахар» \\ (Воронеж, Россия). Приведена методика расчета показателей, необходимых для анализа эффектив- \\ ности использования основных средств предприятия. Рассчитаны и проанализированы показатели \\ использования основных средств предприятия. \\ Текст доклада автора на Общероссийской (национальной) научной конференции «Моисеевские \\ чтения. Культура и гуманитарные проблемы современной цивилизации», которая состоялась 4-5 \\ марта 2020 г. в Московском гуманитарном университете.
}

Ключевые слова: фондоотдача; фондорентабельность; фондоемкость; фондовооруженность; производительность труда

\section{EFFECIENSY ANALYSIS OF USING FIXED CAPITAL ASSETS (EXEMPLIFIED BY LLC “PRODIMEX - SAKHAR”)}

\author{
E. G. Petrova \\ Moscow University for the Humanities
}

\begin{abstract}
The paper considers the performance of LLC "PRODIMEX Sakhar", (Voronezh, Russia). The author provides methods of calculating the indicators that are necessary for the effeciency analysis of using the fixed capital assets of an enterprise. The indicators of using the capital assets of the enterprise are calculated and analysed.

The text of the author's speech at the All-Russian (National) Scientific Conference "Moiseev's Readings. The Culture and Humanitarian Issues of Modern Civilisation", which was held at Moscow University for the Humanities on 4-5 March, 2020.
\end{abstract}

Keywords: fixed-asset turnover; returns on assets; capital investment; capital-labour ratio; workforce productivity

Актуальность статьи обусловлена тем, что основные фонды составляют основу материально-технической базы общественного производства. Объем данных активов определяет величину производственной мощности предприятия, характеризует уровень технической вооруженности труда, повышение которой обусловливает рост обогащения трудовой деятельности, повышение технического уровня общественного производства.

Эффективное использование объектов основных производственных фондов оказывает влияние не только на развитие общественного производства в целом, но и каждого конкретного предприятия в отдельности. Положительная динамика показателей использования объектов основных производственных фондов способствует росту объемов выпуска продукции, выработки продукции, снижению величины затрат на производство продукции, ее трудоемкости, и в конечном итоге - росту прибыльности предприятия.

Обеспеченность основными средствами производства и эффективность их использования оказывают огромное влияние на результаты финансовохозяйственной деятельности предприятия. По существу от эффективности и интенсивности использования основных средств зависит финансовое состояние 
предприятия и конкурентоспособность выпускаемой продукции. Поэтому анализу обеспеченности организаций основными средствами придается важное значение. Анализ поводится с помощью показателей фондоотдачи, фондоемкости, фондорентабельности и фондовооруженности. Показатель фондоотдачи является основным показателем анализа эффективности использования основных средств и рассчитывается как отношение объема выпуска продукции за год (на уровне предприятия) к среднегодовой полной стоимости основных фондов. Фактически показатель показывает отдачу основных фондов, чем выше значение показателя, тем более эффективно используются основные фонды. Это означает, что с каждого рубля основных фондов организация получает больше продукции. Иными словами, на каждый рубль выручки организация затратила меньше основных средств. Фондоемкость является обратной величиной от фондоотдачи. Она характеризует сколько основных производственных фондов приходится на 1 рубль произведенной продукции. Фондоемкость это средняя сумма промышленно производственных основных фондов по первоначальной стоимости деленная на объем выпущенной продукции. Фондорентабельность - коэффициент равный отношению балансовой прибыли ксуммесреднегодовойбалансовой стоимости основныхпроизводственных фондов. Данными для его расчета служит бухгалтерский баланс (Шевченко, 2016).

Фондовооруженность - это показатель, характеризующий стоимость основных средств, приходящихся на одного работника. Фондовооруженность труда определяется как отношение стоимости основных средств предприятия (в сопоставимых ценах) к средней годовой списочной численности работников (рабочих) (Мельникова, 2015).

Рассмотрим один из показателей эффективности хозяйственной деятельности предприятия - эффективность основных производственных фондов на примере ООО «УК ПРОДИМЕКС - Сахар» (г. Воронеж, Россия). Основной вид деятельности «деятельность по управлению финансово-промышленными группами».

Таблища 1. Основные стоймостные показатели ОПФ 2017-2018 г2. Tablt 1. Basic cost figures of FCA, 2017-2018

\begin{tabular}{|c|c|c|c|c|c|c|}
\hline Год & $\begin{array}{c}\text { ОФнг, тыс. } \\
\text { руб }\end{array}$ & $\begin{array}{c}\text { ОФкг, тыс. } \\
\text { руб. }\end{array}$ & $\begin{array}{c}\text { Nраб, } \\
\text { человек }\end{array}$ & $\begin{array}{c}\text { Выручка, } \\
\text { тыс. руб }\end{array}$ & $\begin{array}{c}\text { Прибыль, } \\
\text { тыс. руб. }\end{array}$ & $\begin{array}{c}\text { Износ, тыс. } \\
\text { руб }\end{array}$ \\
\hline 2017 & 9692 & 11285 & 3000 & 397952 & 26365 & 2503 \\
\hline 2018 & 11285 & 13264 & 3000 & 598435 & 40238 & 4806 \\
\hline
\end{tabular}

1. В январе 2017 г. компания приобрела автомобиль грузовой УАЗ-390945 стоимостью 665800 тыс. руб. В июне куплены еще два новых автомобиля грузовой фургон УАЗ-390995 Комби, УАЗ 390995-04 ц/м стоимостью 635 500тыс. руб. каждый. В октябре 2017 г. компания приобрела новое оборудование, общая стоимость которого составила 7755 тыс. руб.

1) Среднегодовая стоимость основных фондов

ОФнг $=9692$ тыс. руб.

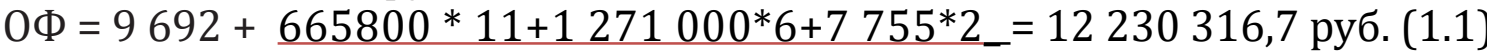

2) Фондовооруженность

Nраб= 3000 чел. 


$$
\Phi \mathrm{B}=\frac{12230316,7}{3000}=4077
$$

4077 руб. приходится на одного работника.

3) Фондоотдача

Выручка = 397952тыс. руб.

$$
\Phi 0=\underline{397952}=0,03
$$

0,03 руб. выручки приносит 1 рубль, вложенный в основные фонды.

4) Фондоемкость

$$
\Phi е ̈=\frac{12230316,7}{397952}=30,7
$$

30,7 руб., вложенных в основные фонды, требуется для производства 1 рубля товарной продукции.

5) Коэффициент износа фондов

ОФкг=11 285 тыс. руб.

Износ $=2503$ тыс. руб.

$$
\text { Кизн }=\underline{2503000}=0,22
$$

$22 \%$ основных фондов износилось за 2017 г.

6) Коэффициент годности

Сост $=11285-2503=8782$ тыс. руб.

$$
\text { Кгодн }=\frac{8872}{11285}=0,77
$$

$77 \%$ основных фондов не износилось и их можно использовать в производстве.

7) Рентабельность основных фондов

Прибыль = 26 365тыс. руб.

$$
\operatorname{Ro} \phi=\frac{26365}{12230316,7}=0,002
$$

0,002 руб. прибыли приходится на 1 рубль, вложенный в основные фонды.

2. 2018 год: В марте 2018 г. Компания приобрела Полуприцеп-самосвал Тонар-9523 стоимостью 1826 тыс. руб. В сентябре был Автомобиль Renault Logan стоимостью 254 тыс. руб. В октябре 2018 г. Компания купила Сетевой накопитель GNAP TS-831 XU стоимостью 102 тыс. руб

1) Среднегодовая стоимость основных фондов

ОФнг=11285тыс. руб.

$$
О Ф=11285+\frac{1826 * 9+254 * 3+102 * 2}{12}=12735000 \text { руб. }
$$

2) Фондовооруженность

Nраб= 3000 чел.

$$
\Phi B=\frac{12735000}{3000}=4245
$$

4245 руб. приходится на одного работника.

3) Фондоотдача

Выручка = 598435тыс. руб.

$$
\Phi O=\frac{598435}{12735000}=0,05
$$

0,05 руб. выручки приносит 1 рубль, вложенный в основные фонды.

4) Фондоемкость 


$$
\Phi \ddot{\mathrm{e}}=\frac{12735000}{598435}=21,3
$$

21,3 руб., вложенных в основные фонды, требуется для производства 1 рубля товарной продукции.

5) Коэффициент износа фондов

ОФкг=13 264тыс. руб.

Износ $=4806$ тыс. руб.

$$
\text { Кизн }=\frac{4806000}{13264000}=0,36
$$

36 \% основных фондов износилось за 2018 г.

6) Коэффициент годности

Сост $=11285-4806=6749$ тыс. руб.

$$
\text { Кгодн }=\frac{6749}{11285}=0,57
$$

$57 \%$ основных фондов не износилось.

7) Рентабельность основных фондов

Прибыль = 40238тыс. руб.

$$
\operatorname{Ro} \phi=\frac{40238}{12735000}=3,16
$$

\begin{tabular}{|c|c|c|c|c|c|c|}
\hline Год & 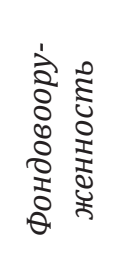 & 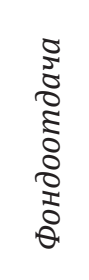 & 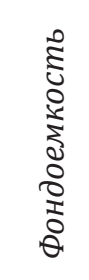 & 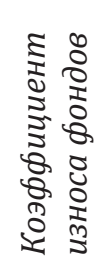 & 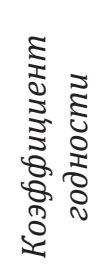 & 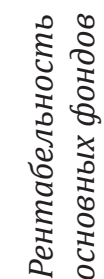 \\
\hline 2017 & 4077 & 0,03 & 30,7 & 0,22 & 0,77 & 0,002 \\
\hline 2018 & 4245 & 0,05 & 21,3 & 0,36 & 0,57 & 3,16 \\
\hline
\end{tabular}

3,16 руб. прибыли приходится на 1 рубль, вложенный в основные фонды.

3. Анализ динамики коэффициентов эффективности фондов

Таблища 2.1. Показатели эффективности основных фондов 2017-2018 г2. Table 2.1. Performance indicators of capital assets, $201-2018$

Таблища 2.2 Динамика показателей эффективности основных фондов Table 2.2. The dynamics of the performance indicators of capital assets

\begin{tabular}{|c|c|c|}
\hline Показатель & Абсолютное изменение & удельное изменение, \% \\
\hline Фондовооруженность & 168 & 4 \\
\hline Фондоотдача & 0,02 & 66 \\
\hline Фондоемкость & $-9,4$ & 44 \\
\hline Коэффициент износа & 0,14 & -64 \\
\hline Коэффициент годности & $-0,2$ & -25 \\
\hline Рентабельность ОФ & 3,14 & 100 \\
\hline
\end{tabular}


В 2018 г. фондовооруженность компании по сравнению с 2017 г. возросла, т. е. количество основных фондов, приходящихся на одного работника, увеличилось. Фондоотдача снизилась, а фондоемкость, наоборот, возросла. Это связано с тем, что выручка компании значительно снизилась, а так как связь между фондоотдачей и выручкой - прямая, а между фондоемкостью и выручкой - наоборот, обратная, то именно этим и объясняется изменение данных показателей. Коэффициент износа увеличился, это говорит о том, что процент износа основных фондов повысился. Коэффициент годности, наоборот, понизился и, таким образом, количество основных фондов, годных для использования, также уменьшилось. Прибыль компании в 2018 г. увеличилась, а, следовательно, и возросла рентабельность основных фондов.

\section{СПИСОК ЛИТЕРАТУРЫ}

Мельникова, Т. В. (2015) Методика проведения анализа основных средств организации // Молодой ученый. № 8. С. 570-573.

Шевченко, А. Ю. (2016) Анализ эффективности использования основных средств на предприятии 000 «Восток» // Молодой ученый. № 19. С. 548-550.

Дата поступления: 10.05.2020 2.

Петрова Елена Геннадьевна - студент факультета экономики и управления Московского гуманитарного книверситета. Адрес: 111395, Россия, г. Москва, ул. Юности, д. 5. Тел.: +7 (985) 136-02-37. Эл. адрес: petrova_elena_69@mail.ru

Petrova Elena Gennadievna, Student, Faculty of Economics, Management and International Relations, Moscow University for the Humanities. Postal address: 5, Yunosti St., Moscow, Russian Federation, 111395. Tel.: +7 (985) 136-02-37. E-mail: petrova_ elena_69@mail.ru

\section{Для цитирования:}

Петрова Е. Г. Анализ эффективности использования основных производственных фондов (на примере 000 «УК ПРОДИМЕКС - Сахар») // Научные труды Московского гуманитарного университета. 2020. №3. C. 37-41. DOI: https://www.doi.org/10.17805/trudy.2020.3.7 